\title{
La enseñanza de segundas lenguas mediante contenidos históricos: un modelo teórico-práctico para el diseño de materiales con el enfoque AICLE
}

Teaching of Second Languages through Historical Contents: A Theoretical-Practical Model for Designing CLIL-Based Materials

O ensino de segundas línguas através de conteúdos históricos: um modelo teórico-prático para o design de materiais com a abordagem CLIL

Ernesto FERRANDO LLIMÓS

orcid.org/0000-0002-437I-5984

Universidad Internacional Iberoamericana, Puerto Rico. ernesto.ferrando@unini.org

Received: 27-09-2018

Accepted by peers: 05-02-2019
Sent for peer review: 15-11-2018

Approved: 07-02-2019

To reference this article (APA) / Para citar este artículo (APA) / Para citar este artigo (APA) Ferrando, E. (2018). La enseñanza de segundas lenguas mediante contenidos históricos: un modelo teórico-práctico para el diseño de materiales con el enfoque AICLE. LACLIL, 11(2), 275-307. DOI: 10.5294/laclil.2018.11.2.5 
RESUMEN. La puesta en práctica de las políticas en materia de enseñanza bilingüe, basadas en el "Aprendizaje Integrado de Contenidos y Lenguas Extranjeras" (AICLE) e impulsadas por distintas directivas europeas y numerosos estudios, representa hoy en día un magnífico campo para la experimentación sobre la didáctica de segundas lenguas a través de contenidos no lingüísticos, como es la historia. No obstante, el carácter multidisciplinar de este entorno educativo, con sus características epistemológicas propias, presenta una dificultad añadida a los docentes de contenido que tienen que desarrollar materiales didácticos que integren tanto la propia didáctica del contenido como la del aprendizaje de segundas lenguas. Sobre la base de esta consideración previa, la presente publicación pretende articular una guía metodológica para el docente, un marco epistemológico que lo oriente en su desarrollo de unidades didácticas en un entorno AICLE. Para este propósito, se expondrán los factores que convergen en el desarrollo de materiales para la enseñanza de segundas lenguas a través de la asignatura de Historia desde dos puntos de vista. El primero, el relativo a la lengua, considerando sus niveles lingüísticos que englobarían tanto el aspecto discursivo del texto histórico como su transposición didáctica y, segundo, desde el propio contenido, en donde se verán, de forma sucinta, los supuestos metodológicos actuales de la didáctica de la historia. El artículo se cierra con una serie de propuestas prácticas de implementación de la teoría expuesta con la historia de España como tema, en español como lengua extranjera.

Palabras clave (Fuente: tesauro de la Unesco): enseñanza de una segunda lengua; educación bilingüe; enseñanza de la historia; formación de docentes; plan de estudios integrado.

ABSTRACT. The implementation of policies on bilingual education, based on the Content and Language Integrated Learning (CLIL) approach and promoted by different European directives and numerous studies, is now a magnificent field for experimentation on the didactics of second languages through non-linguistic content, such as history. However, the multidisciplinary nature of this educational environment, with its own epistemological characteristics, presents an additional difficulty for content teachers who have to develop didactic materials that integrate both the didactics of content and the learning of second languages. Based on this consideration, this publication aims to articulate a methodological guide for the teacher, an epistemological framework that guides him in his development of teaching units in a CLIL environment. For this purpose, the factors that converge in the development of materials for the teaching of second languages through the subject of History from two points of view will be exposed. The first one concerns language, considering its linguistic levels, which would encompass both the discursive aspect of the historical text and its didactic transposition, and the second concerns content itself, where the current methodological assumptions of the didactics of history will be seen. The article closes with a series of practical proposals for the implementation of the theory exposed with the history of Spain as a theme, using Spanish as a foreign language.

Keywords (Source: Unesco Thesaurus): Second language instruction; bilingual education; history education; teacher education; integrated curriculum.

RESUMO. A implementação de políticas de educação bilíngue, baseadas na "Aprendizagem Integrada de Conteúdos e de Língua" (CLIL) e impulsionada por diferentes diretivas europeias e numerosos estudos, representa hoje um campo magnífico para a experimentação no ensino de segundas línguas através de conteúdos não linguísticos, como a história. No entanto, a natureza multidisciplinar desse ambiente educacional, com características epistemológicas próprias, apresenta uma dificuldade adicional para os professores de conteúdo que têm de desenvolver materiais didáticos que integrem tanto a didática do conteúdo quanto a aprendizagem de segundas línguas. Com base nesta consideração anterior, esta publicação visa articular um guia metodológico para professores, um quadro epistemológico que o oriente no desenvolvimento de unidades de ensino em um ambiente CLIL. Com este fim, serão expostos os fatores que convergem no desenvolvimento de materiais para o ensino de segundas línguas através da matéria de História, sob dois pontos de vista. O primeiro, a língua, considerando seus níveis linguísticos que incluiriam tanto o aspecto discursivo do texto histórico como sua transposição didática e, segundo, o próprio conteúdo, onde os atuais pressupostos metodológicos da didática da históriaserão vistos sucintamente. $\mathrm{O}$ artigo conclui com uma série de propostas práticas para a implementação da teoria exposta com a história da Espanha como tema em espanhol como língua estrangeira.

Palavras-chave (Fonte: tesauro da Unesco): ensino de uma segunda língua; educação bilíngue; ensino de história; formação de professores; currículo integrado. 


\section{Introducción}

Pese a que la enseñanza de la historia a través de los enfoques integrados no es reciente, la oferta editorial de materiales de este tipo en español es más bien escasa. En este sentido, destacaríamos los propuestos por el Ministerio de Educación y Formación Profesional y el Ministerio de Cultura y Deporte de España como plan curricular para la enseñanza de la historia de España dirigido a las secciones bilingües de Polonia (Ministerio de Educación y Formación Profesional, 2018), sin olvidar la amplia oferta de cursos universitarios - tanto a nivel nacional, dentro de sus programas Study Abroad, como internacional - de estudios hispánicos, en los que la historia de España cobra un protagonismo importante. Con base en este planteamiento, el punto de partida de este artículo lo debemos fijar en el papel que ocupa la historia en la enseñanza de lenguas extranjeras.

La historia del país del grupo meta, dentro de la enseñanza de segundas lenguas, se ubica entre aquellos conocimientos fundamentales para la consecución del denominado hablante intercultural, concepto ya desarrollado por Kramsch a finales de los años 90 y posteriormente definido por Byram y Zaráte (citados en Byram, 2009) como "aquel discente capaz de establecer lazos entre su propia cultura y otras, de mediar y explicar las diferencias y sobre todo, aceptar dichas diferencias" (pp. 15-16). En este orden de ideas, será Hammerly (citado en Stern, 1992) con su taxonomía de la cultura, quien denominará cultura factual a aquella que habla o informa de hechos que el nativo conoce de su sociedad, como la historia y la geografía o sus héroes y villanos.

En el terreno de los conocimientos culturales, relacionado con el aprendizaje de segundas lenguas, será Stern (1992) quien presentará una división - compuesta de seis aspectos - que se muestra particularmente interesante para fundamentar la importancia de la enseñanza de la historia en el campo de la didáctica de las lenguas extranjeras. El autor, en su clasificación de los conocimientos culturales, ubicará el histórico como uno de aquellos conocimientos que un discente de segunda lengua debe conocer: "the learner needs an oportunity to get to know the significant historical developments 
of the country or region [...] he should get to know the historically significant symbols, [...] notable events and main historical personalities" (Stern, 1992, p. 221). Como señala el autor, este conocimiento debe conducir al aprendiente a conocer el punto de vista del nativo, su percepción histórica o valores - así como antagonismos -, con el objetivo de formar una comprensión histórica del grupo meta desde la empatía, fundamental en el aprendizaje de segundas lenguas, al hilo de la definición de hablante intercultural que hemos citado anteriormente.

En el marco de las observaciones anteriores, conviene indicar la relación existente entre la historia de España y la enseñanza del español como lengua extranjera (ELE), explicitada en el inventario de referentes culturales del Plan Curricular del Instituto Cervantes (PCIC, s.f.) que - junto con los conocimientos que comprenden el de "saberes y comportamientos socioculturales" y el de "habilidades y actitudes interculturales" - refleja aquellos aspectos de ELE no estrictamente lingüísticos pero relacionados directamente con su proyección comunicativa. Como indica en su presentación, desde su afán integrador, este inventario se muestra como una referencia esencial dentro de lo que representa el aprendizaje de ELE al permitir conformar la competencia intercultural del estudiante que se presenta como esencial para comprender, en su máxima amplitud, la cultura española.

Con referencia a lo anterior, con respecto a la relación entre el enfoque de Aprendizaje Integrado de Contenidos y Lenguas Extranjeras (AICLE) y la enseñanza de la historia, podemos citar el estudio de Lamsfub-Schenk (citado en Dallinger, Jonkmann, Hollm y Fiege, 2015). En esta investigación se pudo constatar que, para considerar y evaluar un evento histórico desde múltiples perspectivas, así como comprender la alteridad, podría ser especialmente idóneo el uso del enfoque AICLE, por su enseñanza específica. Por último, es oportuno citar el explícito apoyo que se hace del AICLE en el proyecto Eurydice (2006), en el que se menciona la historia como asignatura a enseñar bajo este enfoque, tanto en la educación primaria como secundaria en todo el ámbito de la Unión Europea, con distintos niveles y tipos de implementación, según el modelo curricular de cada país. Sobre la relación entre el enfoque AICLE y la enseñanza de la historia, se volverá a incidir más adelante. 


\section{Especificidades del lenguaje del contenido: los niveles lingüísticos del discurso histórico y la trans- posición didáctica de los textos}

Como indican Bereiter y Scardamalia (citados en Coyle, Hood y Marsh, 2010), en la sociedad del conocimiento actual, este se adquiere solventando problemas, desarrollando nuevas ideas e interactuando. No obstante, la cuestión central respecto a la enseñanza bilingüe es que, por un lado, el discente en una clase basada en el enfoque AICLE tiene que interaccionar en una L2 (o sea, en una lengua que no domina) y, por otro, que el contenido tiene su lenguaje específico y académico que los alumnos deben conocer. Así pues, en resumen, la integración entre un contenido y una L2 obliga a tener en cuenta no solo la lengua de aprendizaje, sino también la lengua propia necesaria para adquirir los conocimientos del contenido.

Sobre la base de las consideraciones anteriores, citando a Coyle et al. (2010), en el enfoque AICLE se deben considerar tres variables: por un lado, el lenguaje propio del contenido (la historia, como es lógico, tiene su propio lenguaje, que se entiende como la lengua del aprendizaje), la lengua para el aprendizaje y la lengua a través del aprendizaje. En este artículo, únicamente trataremos la primera de ellas — la lengua del aprendizaje o lenguaje propio del contenido - , con enfoque en la exposición en el lenguaje de la historia desgranado a través de las funciones y los géneros discursivos y lo que denominamos la "léxico-gramática" como variables que crean el conocimiento del hecho histórico desde el aspecto lingüístico y que el discente debe conocer (Moore y Lorenzo, 2015).

\section{Niveles lingüísticos del discurso histórico: las funciones discursivas}

Como definición general, la lengua del aprendizaje sería la necesaria para comprender el léxico propio del contenido impartido. No obstante, la cuestión capital que implica el desarrollo de materiales en el entorno AICLE es cómo integrar el contenido con la lengua, asunto sobre el que se profundizará seguidamente. 
Así, sobre la base de estos antecedentes, en el intento de crear una categorización lingüística que sirva a los docentes tanto en el diseño como en la evaluación de materiales, Dalton-Puffer, Bauer-Marschallinger, Brückl-Mackey, Hofmann, Hopf, Kröss y Lechner (2017) identificaron las funciones discursivas (cognitive discourse functions o CDF) como una interfaz, un punto de convergencia entre la lengua y el contenido, es decir, desde la educación específica del contenido y desde la lingüística aplicada, como las dos facetas que identifican a los modelos integrados. Surge así una lista basada en una revisión profunda de la taxonomía de Bloom de más de cincuenta CDF potenciales que luego se compactarán en siete: clasificar, definir, describir, evaluar, explicar, explorar e informar. Esta lista describe de manera coherente y explícita aquellos procesos cognitivos por los que los temas específicos, hechos, conceptos y categorías se verbalizan de manera recurrente. Con base en su teoría sobre CDF, Dalton-Puffer (2011) llevó a cabo un estudio en el contexto educativo austriaco, con el objetivo de analizar el discurso de los discentes de asignaturas como Biología, Economía e Historia, materia que nos ocupa. El estudio, que representa ya una propuesta práctica, presenta de modo estadístico el uso de estas funciones según el contenido del curso. Por ejemplo, en el caso de la asignatura de Historia, se pudieron constatar aquellas funciones que aparecen con más frecuencia, destacando "describir" con un $29 \%{ }^{1}$.

Ahondando en el caso concreto de la historia, destacamos dos modelos que han intentado dar respuesta a la cuestión de integrar este contenido con la lengua meta, mediante un análisis de cómo se emplea el lenguaje en el aula y cómo se construye el conocimiento histórico a través de este. En primer lugar, está el estudio de los géneros discursivos, que se verán en el siguiente epígrafe. En segundo lugar, está el enfoque en el que tratan de integrar la enseñanza de la historia, mediante los modelos propios de su didáctica, con la enseñanza de la lengua meta. Por ejemplo, Staschen y Dielmann (citados en Lackner, 2012) definen la competencia narrativa como la competencia puente esencial que integra el aprendizaje histórico y el aprendizaje de lenguas extranjeras, superando así la separación del contenido y la com-

1 Explicar aparece con un $21 \%$, definir con un $17 \%$, evaluar con un $13 \%$, clasificar con un $11 \%$ y, en último lugar, informar con un $11 \%$. 
petencia lingüística. Este enfoque se fundamenta en el esfuerzo cognitivo que implica la comprensión del hecho histórico, al considerar la multiplicidad de factores que intervienen y que estimulan al discente a desarrollar un discurso más complejo. Así, mediante las funciones discursivas, claves en la competencia narrativa, se consigue poner el foco tanto en los aspectos cognitivos como los lingüísticos (Dielmann, citado en Lackner, 2012).

\section{Niveles lingüísticos del discurso histórico: los géneros discursivos}

Cuando se utiliza el lenguaje, ya sea escrito u oral, se presta atención, de forma consciente o inconsciente, al contexto comunicativo, lo que resulta en la adaptación del lenguaje a los usos - socialmente reconocidos - que se le da. Estos usos o adaptaciones al contexto comunicativo que realiza el hablante constituyen los géneros. Por ejemplo, Martin y Rose (citados en Llinares, Morton y Whittaker, 2012 definen el género como aquel proceso social organizado por etapas orientado a la consecución de un objetivo. En cuanto a esta última definición, el Plan Curricular del Instituto Cervantes para el nivel B2 presenta como géneros, dividiéndolos entre los de trasmisión oral y escrita, las conversaciones cara a cara, los debates o las discusiones públicas, la entrevista laboral, las composiciones escritas, las obras de teatro, etc. Así, sobre la observación anterior, dentro de los géneros de transmisión escrita de solo producción (por ejemplo, el desarrollo de argumentaciones o textos informativos) sobre el Descubrimiento de América, se pueden plantear los siguientes ejemplos de aplicación que pueden servir de guía para el desarrollo de textos (Ferrando, 2018):

a. Sección de introducción. Se hace una contextualización del tema, por ejemplo: "El Descubrimiento de América llevó la civilización a aquel continente, aumentando el nivel de vida de sus habitantes, aunque hay otras teorías que demuestran todo lo contrario".

b. Sección de desarrollo. Es la fase de argumentación para la que se puede utilizar la narración, la descripción, la exposición o la trascripción del diálogo en estilo directo, según el objetivo del escrito. Por ejemplo, partiendo del tema del Descubrimiento de América, una exposición podría, por ejemplo, empezar así: "Tras la llegada de los españoles a América, muchos indígenas empezaron a sufrir 
enfermedades, principalmente la viruela o el sarampión, para las que su sistema inmunológico no estaba preparado...".

c. Sección de conclusión. En esta fase se usarán los marcadores de conclusión, tales como finalmente, en conclusión, etc., así, por ejemplo: "En conclusión, podemos decir que, partiendo...".

Esta forma de entender el lenguaje ha sido de gran ayuda para el estudio de los discursos producidos por grupos específicos de usuarios y también en clase, como por ejemplo en la enseñanza de la lengua para fines específicos. En el ámbito de la historia, se pueden presentar los géneros indicados en la Tabla 1.

Tabla 1. CDF en los textos históricos

\begin{tabular}{|l|l|}
\hline \multicolumn{1}{|c|}{ Nombre } & Estructura (entre paréntesis las opciones) \\
\hline Estudio del periodo & Identificación del periodo $\rightarrow$ Descripción \\
\hline Relato bibliográfico & $\begin{array}{l}\text { Identificación de la persona } \rightarrow \text { Episodios } \\
\rightarrow \text { (Evaluación del periodo) }\end{array}$ \\
\hline Relato histórico & $\begin{array}{l}\text { Antecedentes } \rightarrow \text { Relato de los hechos } \rightarrow \\
\text { (Deducción / evaluación de los hechos) }\end{array}$ \\
\hline $\begin{array}{l}\text { Representación histórica (se } \\
\text { explican las razones que mueven } \\
\text { los acontecimientos ocurridos en } \\
\text { una secuencia determinada) }\end{array}$ & $\begin{array}{l}\text { Antecedentes } \rightarrow \text { Relato de la secuencia } \\
\text { (Deducción) }\end{array}$ \\
\hline Explicación histórica & $\begin{array}{l}\text { Introducción } \rightarrow \text { Consecuencias } \rightarrow \\
\text { (Consecuencias posteriores) }\end{array}$ \\
\hline Explicación de los factores & $\begin{array}{l}\text { Resultado } \rightarrow \text { Factores } \rightarrow \text { (Factores } \\
\text { indirectos) }\end{array}$ \\
\hline Exposición histórica & $\begin{array}{l}\text { Antecedentes } \rightarrow \text { Pregunta de } \\
\text { investigación } \rightarrow \text { Argumento } \rightarrow \text { Otras } \\
\text { preguntas de investigación }\end{array}$ \\
\hline Discusión histórica & $\begin{array}{l}\text { (Antecedentes) } \rightarrow \text { Cuestión } \rightarrow \\
\text { Perspectivas } \rightarrow \text { Posición }\end{array}$ \\
\hline
\end{tabular}

Fuente: Llinares et al. (2012, pp. 133-146).

\section{Niveles lingüísticos del discurso histórico: la léxico-gramática}

Podemos definir la léxico-gramática como las estructuras gramaticales - y el léxico - de uso común que permiten expresar la abstracción, las marcas temporales o las relaciones entre causa y consecuencia en el relato histórico; por ejemplo, las cláusulas introducidas por una 
conjunción temporal o verbo en forma no personal. Achugar y Schleppergrell (2005), al hilo de lo expuesto, se esquematizan las estructuras lingüísticas destinadas a construir la causalidad en historia:

a. Conjunciones y cláusulas de concesión, de causa o propósito, como las locuciones adverbiales, que expanden y desarrollan el argumento; por ejemplo "sin embargo", que puede servir como medio para marcar el contraste entre una acción que, pese a ser esperada, cambia de sentido, como podemos observar en este texto:

"la idea primitiva del plan de invasión tal como la había concebido originariamente el marqués de Santa Cruz, era intentar atravesar nuestra defensa naval con sus transportes. El estudio meditado, sin embargo, convenció al rey de su debilidad (...)". (Martínez-Valverde, 1979, p. 5)

b. Las cláusulas introducidas por una locución preposicional, como "después de", que ayuda a crear el contexto, como marca de unión entre dos eventos dimensionados tanto en lo temporal como en lo causal, como se puede ver en este texto:

"Hubo que continuar adelante, después de disponerse algunos auxilios. Al detenerse la Armada, con buques tan pesados algunos, se hubiese roto la formación. El Nuestra Señora del Rosario estaba hecho una boya: los enemigos le hubiesen batido a mansalva, cruzándole la T. Se rindió a Drake. ¿Influyó él despecho? En la voladura del San Salvador se cree que hubo sabotaje. Flotaba incendiado después de la explosión de la pólvora. Debiera haber sido hundido por su dotación”. (Martínez-Valverde, 1979, p. 6)

c. Formas no temporales del verbo, como el gerundio, para definir una causa, para explicar la razón (como complemento circunstancial de causa) o el infinitivo, a veces precedido de una preposición, como motivador de una acción, por ejemplo:

"La flota no podía zarpar, esperando la llegada de su comandante" y "Pero, de todo modos, para dar en el blanco, con los procedimientos de puntería de la época, había que acercarse más de lo que lo hacían los ingleses en los primeros encuentros". (Martínez-Valverde, 1979, p. 9) 


\section{La transposición didáctica del texto histórico}

Una vez visto cómo se crea el conocimiento histórico desde sus aspectos lingüísticos, cuyo conocimiento incumbe tanto al docente como al discente, en este punto de la exposición se entra en el apartado más dirigido al primero, por estar más focalizado en la creación — o adaptación - de materiales didácticos, en concreto a la adaptación de los textos históricos.

La fuente escrita está indefectiblemente unida a la labor del historiador, siendo, a su vez, el vehículo mediante el cual se materializa el hecho histórico en clase. Para Arteaga y Camargo (2014 ), en relación con el uso de las fuentes como inicio del proceso del pensamiento histórico - concepto sobre el que profundizaremos más adelante cuando se estudie la didáctica de la historia - la la comprensión histórica, a través de los textos, permite al discente:

a. reconocer a la historia como una disciplina que permite comprender procesos ocurridos en el pasado (no vivenciales), así como sus relaciones con el presente;

b. plantear interrogantes e hipótesis, identificar evidencias y validar argumentos en torno a los procesos del pasado y sus relaciones con el presente;

c. comprender de manera reflexiva el nivel de relevancia de los hechos, personajes y/o acontecimientos históricos en cuestión, a partir de conceptos históricos de segundo orden, el manejo de fuentes históricas y el debate en grupo;

d. debatir, a partir de las evidencias planteadas, las diversas y quizás conflictivas historias sobre el pasado planteadas por los historiadores o los testigos de los hechos.

No obstante, en el ámbito de la enseñanza de la historia existe una dificultad añadida: la compresión del texto experto, escrito en un lenguaje académico, puede ser inaccesible para el alumno, lo que exigiría, como seguidamente veremos, su transposición. Mattozzi (2004), a este respecto, señala:

El texto (en la historia) es central, porque de él depende la calidad de lo que comprendemos y aprendemos sobre historia. Todo lo que 
sabemos del pasado se lo debemos a la producción de textos y a la comprensión de los mismos. (p.1)

Al hilo de lo expuesto por el autor, desde el punto de vista de su transposición didáctica, el texto histórico debe ser trabajado tanto desde el aspecto relativo a su estructura - o, lo que es lo mismo, cómo construye el conocimiento - como el que concierne a los recursos lingüísticos que se han usado para construir dicho conocimiento. En las siguientes líneas se verán ambas facetas: primero, se estudiará la transposición del texto desde el punto de vista estructural y a continuación se realizará su transposición lingüística.

En primer lugar, hay que definir qué es un texto histórico. El texto histórico (que puede provenir de una fuente primaria o secundaria ${ }^{2}$ ) se define como aquel texto experto dirigido al lector culto y preparado para entenderlo, opuesto al texto escolar, el cual tiene que ser construido para un lector inexperto con el objetivo de que aumente sus conocimientos y reconstruya sus planteamientos iniciales sobre el hecho en cuestión. Como señala Mattozzi (1999), el texto escolar debe procurar hacer entender al discente el hecho histórico en forma de reconstrucción del pasado, siendo, por lo tanto, una adaptación a la estructura cognitiva del discente. Para una correcta transposición del conocimiento histórico, Mattozzi (1999) lo relaciona con la teoría del aprendizaje de la historia. Partiendo de este principio, desgrana la estructura del conocimiento histórico de la siguiente forma:

a. El docente, como mediador, tiene que trasmitir el conocimiento propio de la historia al discente, así como motivar el desarrollo de una serie de estructuras mentales y habilidades que le permitan comprender el hecho histórico. Para ello, el docente se basará en el conocimiento textual convenientemente estructurado; el texto histórico será modificado, adaptado, partiendo del conocimiento que tenga el docente sobre las estructuras cognitivas y habilidades operativas que actúan como constructoras del conocimiento del hecho histórico desarrollado por el historiador a través del texto. Así pues, el docente debe analizar el texto y hallar en su

2 Los textos de fuente primaria son aquellos escritos en la época que se investiga, contemporáneos a los hechos. Los textos de fuente secundaria, en cambio, son aquellos escritos posteriormente a dicha época. 
estructura las operaciones cognitivas que el historiador usó para desarrollarlo. Partiendo de esta premisa, es clave que el docente sepa ver la "estructura potencial" del texto, que está por debajo de la "estructura real".

b. La estructura potencial del conocimiento histórico como clave para una correcta transposición del texto experto a uno de mediación didáctica. Se parte de la base de que el historiador primero "tematiza" o, lo que es lo mismo, representa el hecho histórico, pasando, para ello, por tres fases:

1. Resalta aquellos aspectos del hecho histórico que pretende presentar;

2. Inscribe el hecho en un periodo de tiempo concreto;

3. Ubica este hecho en un espacio concreto.

Además, para comprender el hecho histórico, este se debe contextualizar para así conocer los motivos que afectaron su comienzo, su desarrollo y su conclusión. Hay que tener en cuenta que el hecho cobra sentido al representar un cambio en el contexto o bien por su consolidación en el mismo. Todo ello forma un "mapa virtual" cognoscitivo compuesto por el escenario que envuelve al hecho, las situaciones iniciales, su comienzo, el consiguiente proceso o evolución, su conclusión, las situaciones finales, las variaciones o las permanencias en los contextos. Dadas las condiciones que anteceden, es importante añadir que el historiador no se contenta con reconstruir el hecho en cuestión, sino que va más allá, puesto que llega a su problematización para dar paso a su explicación, saliéndose así del marco de los hechos relatados y abriéndolo a las comparaciones con otros hechos precedentes.

Tras lo expuesto, conviene prestar atención a cómo el historiador estructura el conocimiento. De forma sucinta se podría decir que el historiador organiza la información en dos bloques textuales: primero, clasifica los temas con la idea de cumplir con las funciones cognitivas concretas y, después, construye con ellos un hilo argumental con fechas o por simultaneidad con otros hechos. Así pues, se puede decir que el conocimiento histórico forma lo que se puede definir como un texto virtual en donde todos los elementos de su estructura se van modificando, se van transformando a través del hilo argumental. Si esto se extrapola a un texto físico, este debe contemplar cada uno de estos bloques que forman la estructura. El resultado debe seguir 
un hilo conductor compuesto de descripción, narración y argumentación. Por las consideraciones anteriores, es vital comprender que cada bloque tiene como finalidad producir en el lector un mapa de conocimientos concatenados con los conocimientos del siguiente bloque. Así pues, el docente tiene que crear este mapa cognitivo de conocimientos huyendo, por lo tanto, de la enseñanza meramente transmisora hacia una más comprensiva, permitiendo que el discente infiera ese mapa cognitivo. Llegada la explicación a este punto, es momento de definir a través de qué fases debe pasar un texto para que se produzca una transposición didáctica:

a. someter el texto experto a un análisis destinado a desvelar su estructura;

b. definir los puntos fuertes que se mantendrán en la transposición y reforzar los débiles (así como aligerarlo, si fuera el caso);

c. crear un primer esquema de configuración, teniendo en cuenta criterios metodológicos sobre la enseñanza de la historia, conceptos cognitivos y lingüísticos;

d. dar al texto nuevo tendrá su propia tematización, estructurado en bloques de conocimiento, en donde cada uno será tematizado;

e. someter el texto resultante, a partir de principios metodológicos-cognitivos, a una segunda configuración, la didáctico-cognitiva, mediante su complementación con otros textos de refuerzo, gráficos, esquemas, etc. para garantizar una mejor comprensión (momento de su estructuración lingüística);

f. definir criterios operativos que ayuden a centrar el proceso de aprendizaje y consolidación de las estructuras cognitivas (fase final, que dará paso al desarrollo de las unidades didácticas).

No obstante, Mattozzi (1999) remarca que hay dos tipos de conocimientos que deben ser protegidos en la transposición: el primero atañe a los hechos y contextos y el segundo a la relación del conocimiento del pasado con el presente. De esta manera, el texto escolar se abre a su interpretación desde el presente, con el añadido de poder servir para interpretar el presente desde ese pasado. Vista la adaptación estructural del texto histórico para su uso didáctico, seguidamente se 
verá la parte correspondiente a la adaptación lingüística citada por Mattozzi (1999).

Martín (citado en Fang, 2012) definirá tres tipos de "cosas" —nociones-, desde el punto de vista de la gramatical nocional, que se pueden encontrar en un texto:

a. las concretas, que hacen referencia al mundo real (navío, etc.);

b. las abstractas, que no hacen referencia al mundo real (política, gobierno, etc.);

c. las metafóricas, tales como las nominalizaciones verbales ("llegar" a "la llegada").

Las tres pueden aparecer en un texto histórico. Tanto las representaciones abstractas como las metafóricas deben tenerse en cuenta, puesto que pueden dificultar su comprensión, por lo que es recomendable "desempaquetarlas" previamente. Por ejemplo, Achugar y Schleppegrell (2005) proponen, en el caso de la nominalización, presentar la información de forma previamente explícita. Al respecto, Jolly y Bolitho (citados en Pueyo y Martí, 2014) remarcan la necesidad de la concienciación textual y pedagógica de los materiales en su propuesta para el diseño de un programa, abriendo así la fase de adaptación lingüística del texto experto. A este respecto, Lorenzo (2008) plantea tres opciones para adaptar un texto desde el punto de vista de su contenido lingüístico (Tabla 2):

Tabla 2. Opciones metodológicas para el ajuste de un texto

\begin{tabular}{|c|c|c|c|}
\hline PROCESO & $\begin{array}{c}\text { Nivel de } \\
\text { adaptación }\end{array}$ & Objetivo & Estrategias \\
\hline 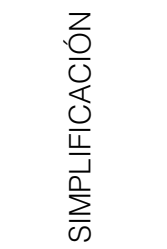 & Sentencia & $\begin{array}{l}\text { Reducir la } \\
\text { complejidad } \\
\text { lingüística }\end{array}$ & $\begin{array}{l}\text { Usar vocabulario más común } \\
\text { Limitar el rango sintáctico y } \\
\text { semántico (es decir, el nivel de } \\
\text { abstracción) }\end{array}$ \\
\hline 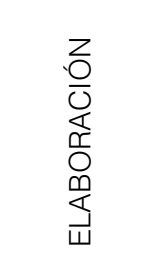 & Texto & $\begin{array}{l}\text { Elaborar el texto } \\
\text { para hacerlo } \\
\text { más simple o } \\
\text { cognitivamente } \\
\text { más fácil }\end{array}$ & $\begin{array}{l}\text { Resaltar los conceptos más } \\
\text { importantes } \\
\text { Añadir redundancias } \\
\text { Plantear un texto con pocas } \\
\text { palabras diferentes con respecto } \\
\text { al total de palabras }\end{array}$ \\
\hline
\end{tabular}




\begin{tabular}{|c|c|c|c|}
\hline PROCESO & $\begin{array}{c}\text { Nivel de } \\
\text { adaptación }\end{array}$ & Objetivo & Estrategias \\
\hline 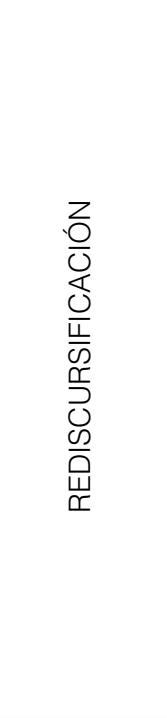 & Discurso & $\begin{array}{l}\text { Rediseñar el } \\
\text { texto completo } \\
\text { Adaptar su } \\
\text { significado a } \\
\text { una nueva forma } \\
\text { y formato. }\end{array}$ & $\begin{array}{l}\text { Cambiar la tipología del } \\
\text { texto: menos ideacional y } \\
\text { más interpersonal, es decir, } \\
\text { más interactivo (por ejemplo, } \\
\text { añadiendo preguntas en el texto) } \\
\text { Añadir marcas que refuercen el } \\
\text { significado, que lo hagan más } \\
\text { explícito } \\
\text { Reducir el vocabulario técnico } \\
\text { por uno semi técnico. } \\
\text { Reducir las ideas secundarias, } \\
\text { hacerlo más concreto } \\
\text { Añadir notas complementarias al } \\
\text { texto, como glosarios, gráficos, } \\
\text { imágenes, información entre } \\
\text { paréntesis, etc. }\end{array}$ \\
\hline
\end{tabular}

Fuente: (Lorenzo, 2008).

De las tres opciones, el autor se decanta por la rediscursificación (como restructuración de ideas) con base en cuatro principios, sobre la idea principal de que el texto no debe perder su peso académico:

a. El texto se adapta a los discentes, no lo contrario.

b. La rediscursificación permite convertir el texto científico en uno pedagógico al cambiar el autor el vocabulario técnico por uno semitécnico, más reconocible para el discente.

c. El texto rediscursificado es más explícito y delimitado que extenso, siendo este un punto importante en la enseñanza bilingüe.

d. El autor del texto - gracias al uso de ayudas visuales, glosarios e información entre paréntesis — reduce la complejidad lingüística o carga cognitiva del texto original.

\section{Aproximación a la metodología de la didáctica de la historia: el pensamiento histórico}

Así pues, y tras lo expuesto hasta ahora, se podría decir que el desarrollo de materiales didácticos de este tipo debe contemplarse 
como un proceso holístico, de suma de variables, en donde confluyen los conocimientos, metodologías y enfoques de dos grandes áreas del conocimiento, como son la enseñanza de idiomas (con sus enfoques y metodologías) y, como vamos a ver en este epígrafe, la didáctica de la historia. El resultado de la suma de ambas debe conducir a una integración óptima entre la lengua y el contenido.

La idea principal que rige la didáctica de la historia es el concepto de pensamiento histórico. Sin ser nuevo, este concepto ha cobrado últimamente gran importancia de la mano de autores como Carretero y Montanero (2008), Santisteban (2010), Prats y Santacana (2011) o Seixas y Norton (2013), entre otros, frente al tradicional método memorístico. Este concepto parte de la premisa de que para comprender la historia hay que pensar históricamente, dejando a un lado, como decimos, la mera memorización de nombres, hechos o fechas. Mediante el pensamiento histórico se interpreta el pasado a través de la evaluación y la crítica de las evidencias (textos escritos o icónicos, como fuentes de información) y aplicando los procesos mentales propios de la comprensión histórica; por ejemplo, para Seixas y Norton (2013), el pensamiento histórico suministra al discente la posibilidad de pensar más allá de la inmediatez, a comprender las interacciones existentes entre los contextos sociales, económicos, etc. y los personajes implicados. Autores como Kitson et al. (2015) añaden que el pensamiento histórico implica, a su vez:

a. comprender la naturaleza de la evidencia (que nace en el historiador);

b. comprender que las personas del pasado no eran como las actuales;

c. comprender el cambio que acontece con el tiempo y su influencia en el presente;

d. comprender las interpretaciones históricas.

En el campo de la enseñanza de la historia, podemos definir dos grandes tipos de métodos: el expositivo y el aprendizaje por descubrimiento - sin olvidar la más que posible tendencia actual al eclecticismo (Prats y Santacana, 2011) - . El primero hace referencia al método clásico - el de la clase magistral —, en el que el discente es el receptor pasivo de una serie de informaciones suministradas por el docente que asume el papel de agente activo, como director de la clase. Huelga 
decir que es el más clásico de los métodos usados en la enseñanza de la historia, pero también el menos recomendable, al menos en su estado digamos "puro".

El segundo método hace al discente el centro de la actividad, relegando al docente a un mero mediador. En el método por descubrimiento - o indagativo - de corte constructivista, es el discente quien descubre, deduce y elabora explicaciones históricas. El punto de apoyo de este método indagativo es la resolución de problemas. Los mismos autores presentan una lista de formatos prácticos para el desarrollo de materiales didácticos, dejando la puerta abierta a otros, siempre teniendo en cuenta que es clave considerar la selección de contenidos, su adecuada secuenciación y el progresivo planteamiento de retos y soluciones de problemas que resolver (Prats y Santacana, 2011):

a. Situación-problema. A partir de una pregunta y una exposición de una situación dada, se plantea la resolución de cuestiones que el alumno debe dilucidar.

b. Estudio de caso único. Se trata de partir de un tema muy acotado y con suficientes datos aprehensibles y analizables que permiten recomponer una explicación.

c. Trabajo por proyectos. Se trata de ofrecer la posibilidad de realizar una "investigación" que construya un informe, partiendo de un tema que desarrollar con pautas adecuadas de planificación, estrategias de observación de la información y pre esquemas de redacción.

d. Juegos de simulación. Se plantean estratégicas de resolución de problemas en la forma de juego. Esta orientación debe ser considerada con atención por parte de los docentes, sobre todo por la proliferación e implementación de juegos "históricos" multimedia e interactivos que proliferan en el mercado.

e. Dramatizaciones o simulaciones. Son una actividad clásica que, en los últimos tiempos, se ha convertido en la realización de reportajes en vídeo o representaciones dramatizadas en las que los discentes ocupan el lugar de los personajes históricos.

Tras lo expuesto, conviene prestar atención a los recursos didácticos de que dispone el docente para conseguir que el discente aprenda 
a pensar históricamente. Carretero y Montanero (2008) dividen estos recursos en dos grupos: los basados principalmente en textos orales o escritos y los que se fundamentan en información de naturaleza icónica. En el primer grupo se ubicaría la clásica explicación verbal del docente que se materializa en la descripción de los hechos, las fechas y los personajes. Las explicaciones verbales deben motivar la capacidad comprensiva de los discentes para que sean capaces de enlazar tanto las ideas como los argumentos que las sustentan. Sin embargo, una buena explicación debe proporcionar ciertos apoyos que den coherencia al discurso, que ayuden a comprender las relaciones entre las ideas, clarificando o evocando la información implícita o conocimientos previos (Sánchez, Rosales, Cañedo y Conde, citados en Carretero y Montanero, 2008).

Para una correcta comprensión del hecho histórico es necesario contextualizarlo; el docente debe proporcionar información que clarifique las intenciones de los personajes, las razones económicas, sociales, etc., que los envuelven (Carretero y Montanero, 2008). En esta línea, conviene remarcar que la participación del discente es crucial (con trabajos en grupo) y su evaluación debe basarse en ella. Por tal motivo, el docente debe plantear cuestiones tales como inferir posibles desenlaces (según los acontecimientos que se estudian) o posibles factores causales que influyeron o que justifiquen el porqué de esa influencia (Carretero y Montanero, 2008). Es muy recomendable plantear preguntas tales como "¿qué harías tú si fueras...?” o aquellas que evocan planteamientos comparativos entre el presente y aquel pasado.

\section{El enfoque AICLE. Principios de articulación entre la didáctica de la historia y la didáctica de las lenguas}

En la introducción se ha tenido la oportunidad de exponer de forma sucinta las ventajas que aporta el enfoque AICLE para la enseñanza de la Historia. En efecto, para Navés y Muñoz (2000) un idioma se aprende mejor en un ambiente natural y el enfoque AICLE proporciona esa naturalidad al contextualizar la lengua con un contenido curricular. Citando a la asignatura de Historia, las autoras señalan que: 
El Aprendizaje Integrado de Lenguas Extranjeras y otros Contenidos Curriculares implica estudiar asignaturas como la Historia o las Ciencias Naturales en una lengua distinta de la propia. El AICLE resulta muy beneficioso tanto para el aprendizaje de otras lenguas (francés, inglés,...) como para las asignaturas impartidas en dichas lenguas. El énfasis del AICLE en la "resolución de problemas" y "saber hacer cosas" hace que los estudiantes se sientan motivados al poder resolver problemas y hacer cosas incluso en otras lenguas. (Navés y

Muñoz, 2000, p. 2)

Conviene resaltar cómo las autoras relacionan el enfoque AICLE con la "resolución de problemas", coincidiendo con los planteamientos, ya expuestos por Prats y Santacana (2011), en lo relativo a la didáctica de la historia. Así pues, tal y como se observa, se puede inferir que el enfoque AICLE y la didáctica de la historia coinciden en sus planteamientos didácticos, ambos de base cognitiva. En este punto, cabe agregar que, por su fuerte orientación hacia el uso del lenguaje con propósitos comunicativos, será el aprendizaje por tareas el que fundamente el enfoque AICLE. Así, mediante las situaciones que crean las tareas, el discente perfecciona su habilidad lingüística a la vez que aprende los contenidos no lingüísticos, usando para ello estrategias comunicativas. Para finalizar, cabe agregar que no es el propósito de este artículo profundizar en este tipo de aprendizaje y se dirige al lector al siguiente apartado, en el que se hace referencia a la estructura - basada en pretarea, tarea y post-tarea - usada para desarrollar la propuesta de diseño de unidades didácticas expuesta en el mismo apartado. Conviene indicar que este modelo tripartito parte de las investigaciones llevadas a cabo por autores como Estaire y Zanon (1994), Skehan (1996), Willis y Willis (2007) y Moore y Lorenzo (2015), entre otros.

\section{Materiales bilingües. Propuesta de estructura para el diseño de unidades didácticas para la enseñanza de la historia de España en español como lengua extranjera}

A nuestro modo de ver, un marco metodológico para el diseño de unidades didácticas podría seguir el siguiente esquema: plantear una exposición de los acontecimientos, personajes y hechos significativos (las 
guerras, los grandes hitos y las biografías) del país del grupo meta, que sirva como base para que el alumno piense históricamente (Prats y Santacana, 2011) y comprenda, de manera reflexiva, el nivel de relevancia de los hechos históricos (Carretero, 2008; Symcox y Wilschut, 2009; Santisteban, 2010; Prats y Santacana, 2011; Seixas y Norton, 2013). Para tal fin, se pueden plantear investigaciones que partan de una pregunta dada (Kitson et al., 2015) o reflexiones y debates sobre textos provenientes de fuentes primarias y secundarias, incentivando tanto la interpretación de la historia como la comprensión del proceso de construcción del relato histórico.

Es importante resaltar que para el contraste de ideas es muy útil trabajar el mismo hecho histórico desde distintos puntos de vista, considerando la importancia de la dimensión humana o planteando un juicio moral de hechos y personajes, siempre desde el respeto (Santisteban, 2010). Se puede ver un ejemplo de este tipo en la Tarea 2.b, que se expone más adelante.

\section{Integración de contenido y lengua}

Sobre las distintas experiencias investigadoras en materia de integración entre un contenido y una lengua extranjera, como son los trabajos de Dalton-Puffer et al. (2017) y Lackner (2012) sobre las funciones discursivas (de las que ya se ha hecho mención más arriba) en el ámbito de la historia, se ha confeccionado la siguiente tabla (Tabla 3) que relaciona los modelos discursivos, las funciones discursivas y las correspondientes estructuras, como variables lingüísticas que relacionan el contenido histórico con la lengua (Ferrando, 2018) y que pueden servir de guía al docente en el desarrollo de tareas.

Tabla 3. Modelos discursivos en los textos históricos

\begin{tabular}{|l|c|l|}
\hline MODELOS DISCURSIVOS & $\begin{array}{c}\text { FUNCIONES } \\
\text { DISCURSIVAS }\end{array}$ & EXTRUCTURAS (Ejemplos) \\
\hline $\begin{array}{l}\text { Organizar datos históricos // } \\
\begin{array}{l}\text { Secuenciar fechas } \\
\text { históricas, etc. }\end{array}\end{array}$ & Clasificar & $\begin{array}{l}\text { Establece una relación... // } \\
\text { ¿Qué relación crees que...? } \\
\text { // Clasifica, etc. }\end{array}$ \\
\hline
\end{tabular}




\begin{tabular}{|c|c|c|}
\hline MODELOS DISCURSIVOS & $\begin{array}{l}\text { FUNCIONES } \\
\text { DISCURSIVAS }\end{array}$ & EXTRUCTURAS (Ejemplos) \\
\hline Describir imágenes, etc. & Describir & $\begin{array}{l}\text { ¿Qué ves? // En esta foto } \\
\text { podemos ver..., etc. }\end{array}$ \\
\hline $\begin{array}{l}\text { Opinar sobre una cuestión } \\
\text { histórica // Buscar } \\
\text { información sobre un tema } \\
\text { concreto, etc. }\end{array}$ & Evaluar & $\begin{array}{l}\text { Pensamos que } \\
\text { podríamos...// ¿Qué } \\
\text { característica en tu opinión } \\
\text { es...? Etc. }\end{array}$ \\
\hline $\begin{array}{l}\text { Analizar textos históricos } \\
\text { de fuente primaria y } \\
\text { secundaria, etc. }\end{array}$ & Explicar & $\begin{array}{l}\text { ¿De qué trata el texto? // } \\
\text { ¿Quiénes eran los...? // } \\
\text { ¿Cuál fue...? // ¿Dónde? // } \\
\text { ¿Quiénes? Etc. }\end{array}$ \\
\hline $\begin{array}{l}\text { Narrar acontecimientos // } \\
\text { Desarrollar el mapa de una } \\
\text { historia }\end{array}$ & Narrar & $\begin{array}{l}\text { ¿Qué era España antes de } \\
\text { la unión de los reinos de } \\
\text { Castilla y Aragón? }\end{array}$ \\
\hline $\begin{array}{l}\text { Identificar las condiciones } \\
\text { sociales, etc. }\end{array}$ & Definir & $\begin{array}{l}\text { Yo creo que es modernista } \\
\text { porque utiliza... etc. }\end{array}$ \\
\hline $\begin{array}{l}\text { Formular hipótesis // Debatir } \\
\text { sobre acontecimientos } \\
\text { históricos, etc. }\end{array}$ & $\begin{array}{l}\text { Realizar } \\
\text { hipótesis }\end{array}$ & $\begin{array}{l}\text { Sí España hubiera....// Yo } \\
\text { creo que... etc. }\end{array}$ \\
\hline
\end{tabular}

Fuente: Ferrando, 2018.

\section{Diseño de unidades didácticas. Tareas: secuencia integrada}

Sobre la base de las consideraciones expuestas en los anteriores epígrafes, seguidamente se presenta la estructura de una unidad didáctica basada en tareas y partiendo de la propuesta tripartita de Moore y Lorenzo (2015), que sirve de ejemplo para poner en práctica, de forma resumida, la teoría explicitada. Es importante indicar que, por motivos de espacio, no se presentan ni los textos ni las tareas orientadas a su comprensión, por lo que las tareas expuestas no seguirían estrictamente este orden de presentación.

Inicialmente, tras la definición del nivel de L2 de la unidad³ ${ }^{3}$, se desglosa su contenido tanto estructural y lingüístico como temático. Así, y a modo de presentación, la unidad didáctica podría estar encabezada por la siguiente información (Ferrando, 2018):

3 Para Moore y Lorenzo, (2015), se debe tener en cuenta tanto el MCER, en lo referente al nivel de lengua, como también el nivel educativo del grupo meta, en relación con su madurez intelectual. 
a. Título (por ejemplo: "Los Reyes Católicos y el Descubrimiento de América”)

b. Temas que componen la unidad didáctica (por ejemplo: La España de los Reyes Católicos - La economía y las gentes en tiempos de los Reyes Católicos - La Inquisición - El Plateresco - El choque de civilizaciones)

c. Modelos discursivos (por ejemplo: describir imágenes, analizar textos, relacionar imágenes, organizar datos históricos, etc.)

d. Tareas que componen la unidad didáctica (esquematizar un texto, análisis de un monumento arquitectónico, realización de una exposición de arte, etc.)

e. Contenidos lingüísticos, que se dividen en:

1. Funciones lingüísticas

2. Vocabulario

3. Temporización

Después de lo anterior expuesto, seguidamente desarrollaremos la secuencia de tarea sobre la base del modelo tripartito de Moore y Lorenzo (2015):

\section{Fase A. Pre-tarea}

Fase predominantemente comunicativa, en donde se introduce el tema de la unidad didáctica. Es el momento de una exposición introductoria del profesor que permita establecer las relaciones entre la nueva información y la que ya poseen los alumnos ${ }^{4}$ mediante, por ejemplo, un texto - escrito o hablado, con el que además verán las estructuras gramaticales (funciones) en su contexto - tareas de activación del vocabulario específico del contenido (Tarea 1.c, Ferrando, 2018), una batería de preguntas (Tarea 1.a, Ferrando, 2018) o bien planteando una “tormenta de ideas" en clase (Tarea 1.b, Ferrando, 2018). Con referencia a lo anterior, es muy recomendable usar recursos icónicos (de bajo esfuerzo cognitivo), tales como los mapas geográficos, las fotografías o el arte como excelente medio, en todas sus expresiones, para una primera aproximación al periodo histórico en cuestión, que además favorece la

4 Sería la fase de Priming de Willis y Willis (2007). 
madurez intelectual — gracias a que propicia el trabajo autónomo desarrolla el gusto estético (Trepat, citado en Prat y Santacana, 2011) y permite al docente introducir aspectos culturales (Moore y Lorenzo, 2015) sobre la vida cotidiana, la gastronomía, la vestimentas, etc. de la sociedad del pasado. Es la fase para establecer los criterios evaluativos e introducir el modus operandi (Moore y Lorenzo, 2015). A su vez, esta fase debe servir al profesor para conocer los puntos débiles y fuertes del grupo, en todos los aspectos tanto en lo relativo al contenido como al lingüístico y hacer los pertinentes ajustes, si fuera el caso.

Tarea 1.a. Introducción de los nuevos conocimientos. ¿Qué conoces del descubrimiento de América? ¿Quién crees que dijo esta frase? "Quiero ir a las Indias por el oeste. La Tierra es redonda".

Tarea 1.b. Observad estas imágenes (Figuras A, B y C) y comentadlas en grupo.

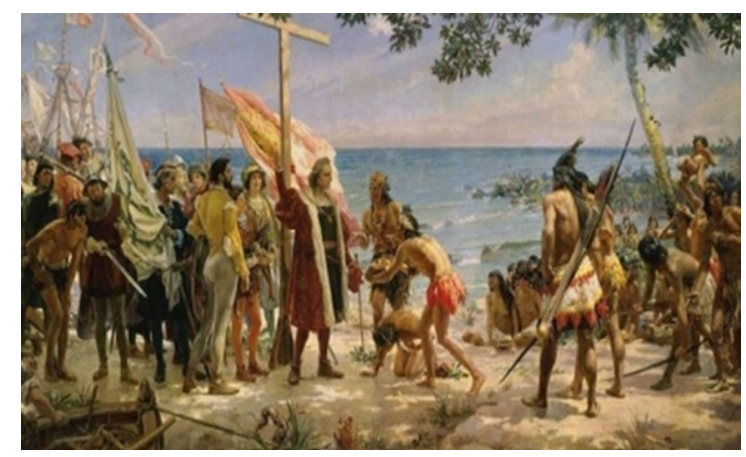

Figura A*

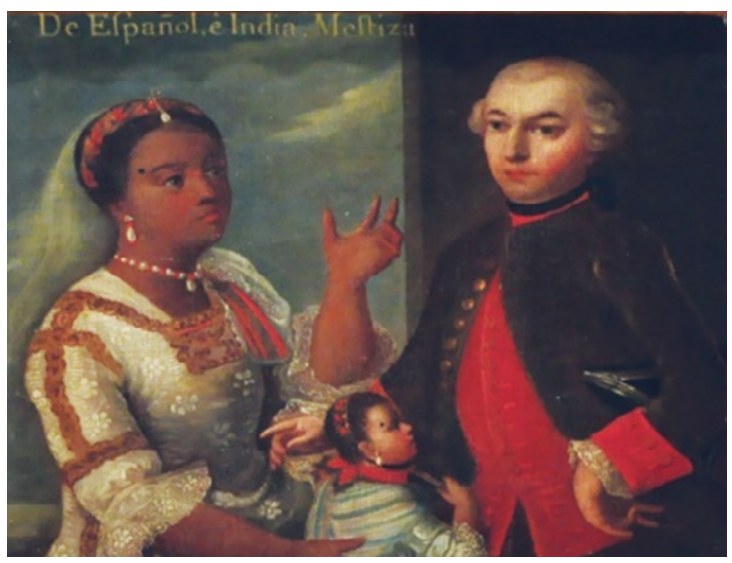

Figura B* 


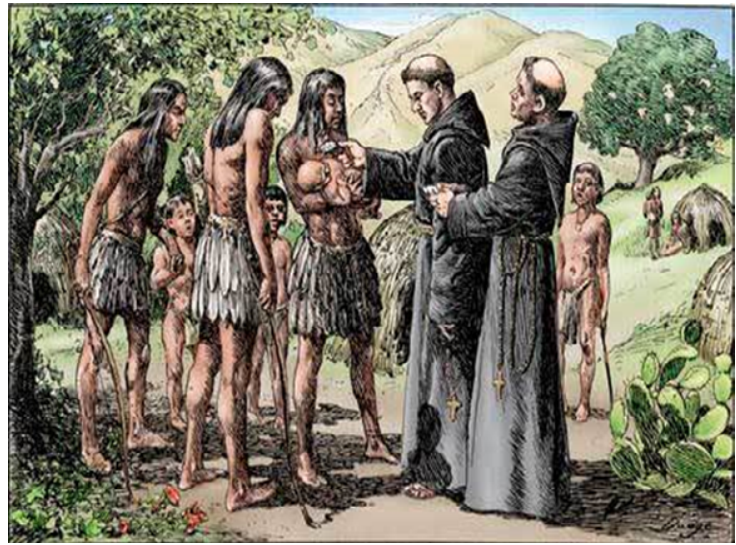

Figura $C^{*}$

* Las imágenes hacen parte de Ferrando (2018) y fueron recuperadas de: Figura A (s.f). Colón llega a América. Recuperada de: https://www.elpandelospobres.com/ primer-homenaje-colon; Figura B (s.f): Español e india mestiza. Recuperada de: https://www.3museos.com/?pieza=de-espanol-e-india-mestiza; Figura C (s.f): Evangelización de América. Recuperada de http://www.celam.org/cebitepal/detalle_d.php?id=NjI

\section{¿Qué relación puede haber entre ellas? ¿Qué títulos les pondrías?}

Tarea 1.c. Activación del nuevo vocabulario. En grupos, y partiendo de los textos que ya habéis leído sobre los Reyes Católicos, usad estas palabras (Figura A) para escribir frases verdaderas.

Figura A. Nube de palabras

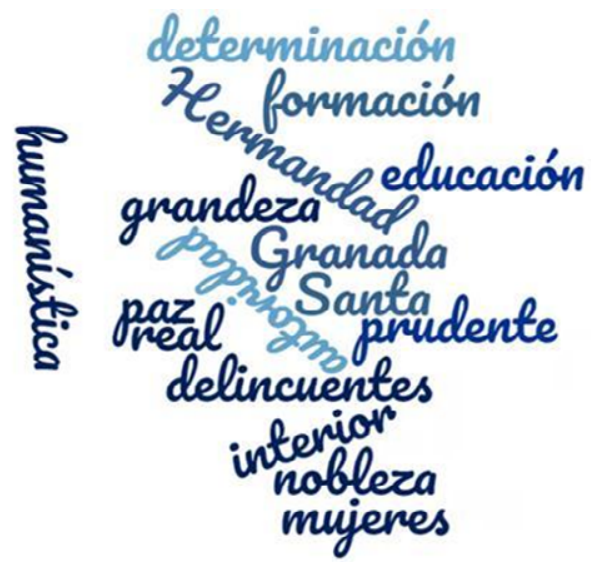

Fuente: elaboración propia. 


\section{Fase B. Tarea}

Es el núcleo del ciclo de tarea e implica comprender el contenido y producir lengua con un equilibrio entre forma y significado. Como punto de referencia, en esta fase debe haber tiempo para hablar, pensar y participar mediante unas tareas que presenten un equilibrio entre un input (textos escritos o textos orales) y un output (hablar y escribir) (Moore y Lorenzo, 2015). Cabe agregar que esta fase puede estar constituida por actividades conducentes a una tarea final, precedidas por unas actividades presentadas de forma secuencial - por ejemplo, que conformen un proyecto - o bien por un bloque de tareas que se complementen entre ellas. En este punto, el docente estará atento al aporte del andamiaje (tanto el relativo al contenido como al de la lengua) necesario, así como a cualquier problema que pueda surgir durante el proceso de producción de los alumnos. En este orden de ideas, resulta oportuno citar a Dodge (2001), quien plantea tres tipos de andamiajes: recepción, transformación y producción.

El un andamiaje de recepción es necesario para que el discente extraiga la información necesaria para el desarrollo de la tarea; el andamiaje de transformación ayuda al discente a realizar tareas como comparar, valorar o decidir; y el andamiaje de producción está tiene como objetivo guiar al discente a crear, entre otras cosas, plantillas o guiones de escritura.

Sobre estos planteamientos, y poniendo el foco en el ámbito de la enseñanza de la historia, el andamiaje del contenido puede estar basado, por ejemplo, en ilustraciones con etiquetas y leyendas o un video. Los gráficos organizadores y las tablas también ocupan un puesto importante como medio para realizar un correcto andamiaje puesto que sirven para hacer que el discente entienda y recuerden información nueva más fácilmente. Por último, es interesante citar el andamiaje mediante las Tecnologías de la Información y de las Comunicaciones (TIC), como las presentaciones en PowerPoint ricas en mapas y gráficos o la búsqueda de información por internet mediante actividades estructuradas y guiadas por el profesor (Webquests) que posibilitan el trabajo cooperativo orientado al descubrimiento, análisis, síntesis o selección del material más adecuado para el desarrollo de la tarea propuesta. Sobre las preguntas de los textos presentados, estas deben 
relacionar los objetivos del contenido con el lenguaje requerido. En este sentido, es muy útil proporcionar las bases para guiar la producción del discente (como andamiaje de la lengua), de menor a mayor dificultad (Guerrini, 2009), por ejemplo mediante comienzos de oraciones ("La Contrarreforma fue la respuesta a la Reforma de..."), mediante preguntas (“¿Qué fue la Contrarreforma?”) o bien con instrucciones (“Haz una lista de las razones de Lutero para romper con el Papa") (Ferrando, 2018).

Hechas las consideraciones anteriores la tarea final puede estar basada en: simulaciones, debates, presentaciones en clase, etc. Resolución de problemas y presentación de las soluciones, comparar, resumir y evaluar. Dibujar mapas o producir, por ejemplo, textos. Desde el punto de vista de la didáctica de la historia, es decir del contenido, esta fase debe estar orientada a la comprensión del hecho histórico (Tarea 2.a, Ferrando, 2018), como ya se ha visto en el Proyecto Euroclio5, mediante la aplicación del pensamiento crítico, la creatividad y la toma de decisiones que implica la resolución de problemas. Un ejemplo de tarea final sería la planteada en Tarea 2.b (Ferrando, 2018).

Tarea 2.a. Esquematización de un texto. Partiendo de un texto dado, se le pide a los discentes que lo esquematicen extrayendo la información necesaria para entender la relación entre causa y efecto, así como las variables que influyeron en el devenir de los hechos expuestos (Tabla 4).

Tabla 4. Esquematización de un texto

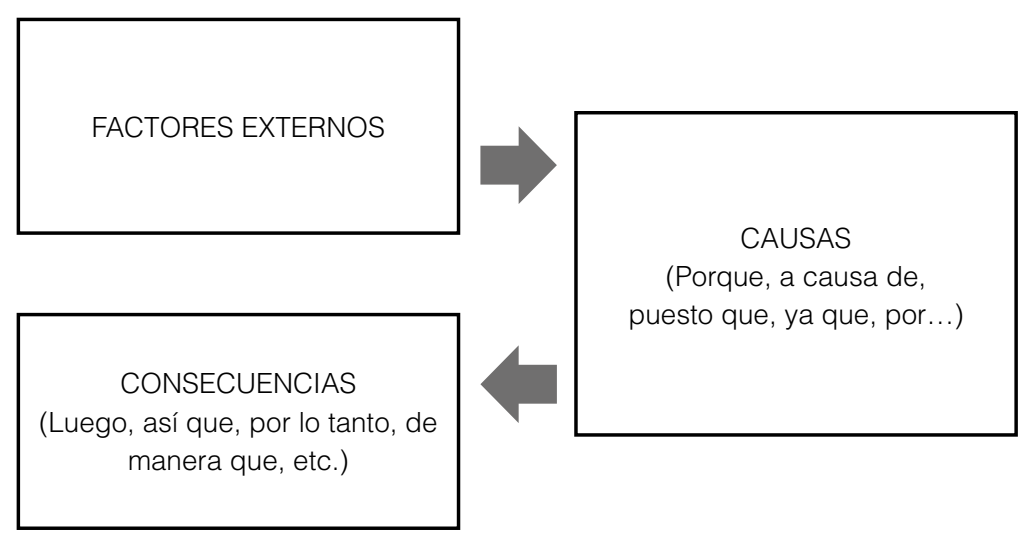

Fuente: elaboración propia.

5 Para más información, visite la página https://euroclio.eu/. 
Tarea 2.b. El Descubrimiento de América a juicio. En esta tarea vais a plantear un juicio, a modo de debate, sobre el Descubrimiento de América. Para ello la clase se dividirá en dos grupos. Cada grupo tendrá que defender lo siguiente:

» El primer grupo defenderá a los indios que se niegan a ser colonizados, defendiendo sus derechos, como pueblo libre, y su cultura

» El segundo defenderá a los españoles y sus derechos a colonizar, a abrir nuevas rutas comerciales, a evangelizar, etc.

Cada grupo aportará sus argumentos; por ejemplo, más abajo tenéis algunos (Tabla 5), pero podéis buscar más (imágenes también). Escribid antes los argumentos que luego utilizaréis en el debate, que pueden ser argumentos alternativos o soluciones para evitar los problemas que hubo. El profesor hará de juez.

Se valorará la calidad comunicativa, la búsqueda imaginativa de argumentos reales así como la organización de las ideas durante el debate.

Tabla 5. Argumentos a favor y en contra

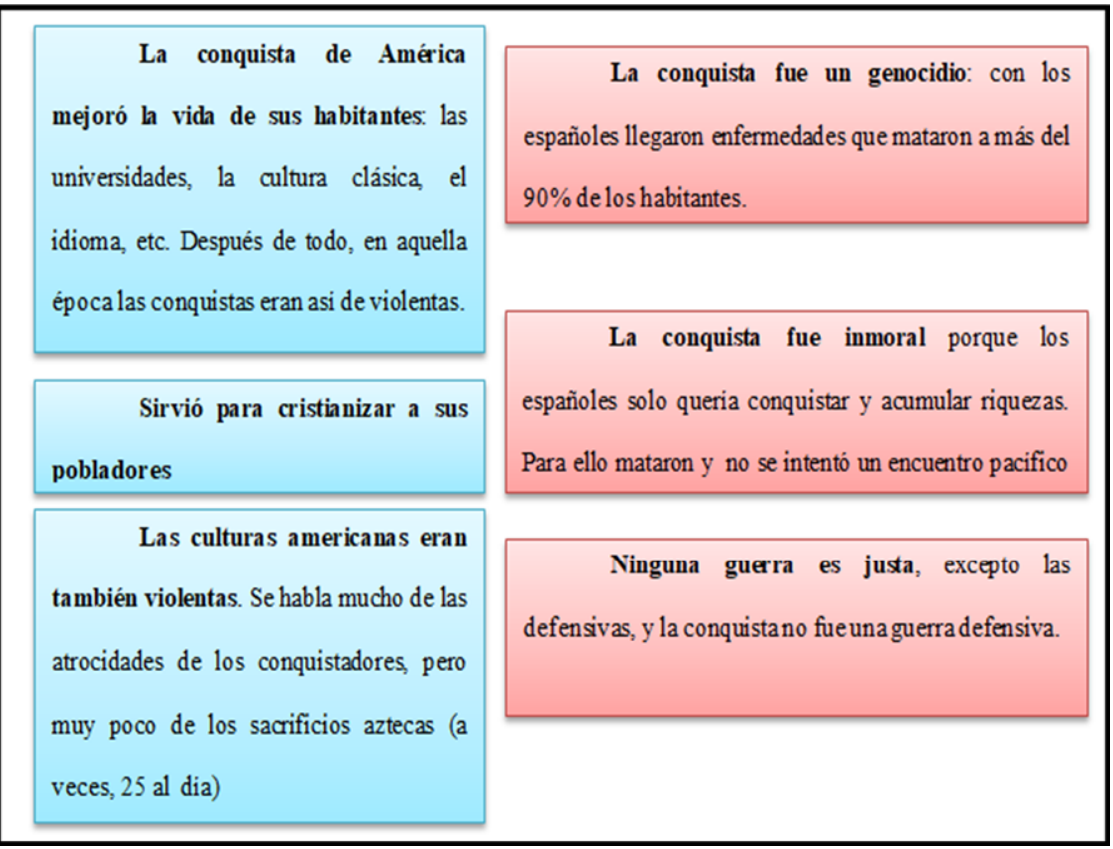

Fuente: elaboración propia. 


\section{Fase C. Post-tarea}

Esta última fase se centra principalmente en la forma a través de la revisión de conceptos y estructuras gramaticales vistas en las fases anteriores. También pueden incluirse en este punto la autoevaluación, tanto a nivel de grupo como individualmente, así como el repaso de las estrategias de aprendizaje que han servido para el desarrollo de la tarea final y que pueden ser útiles para las tareas siguientes. Como fase centrada principalmente en la forma, y citando la propuesta de Willis y Willis (2007), lo importante, a la hora de su desarrollo, es que los alumnos identifiquen de forma explícita aquellas estructuras gramaticales que han visto durante el ciclo de tareas y que, a su vez, estas sean segregadas y trabajadas individualmente. No obstante, conviene tener en cuenta que, por ser un enfoque integrado, la tarea (o tareas) que conforma esta fase debe estar contextualizada con el contenido histórico. En este propósito, la Tarea 3.a sirve de ejemplo de esta contextualización. Por último, citando de nuevo a Willis y Willis (2007), en esta fase se pueden presentar los contenidos de la siguiente unidad didáctica e incluso proporcionar algún tipo de material (un cuestionario o texto), para que puedan trabajarlo fuera de clase.

Tarea 3.a. ¿Indicativo o subjuntivo? Presta atención a la Tabla 6 y usa el INDICATIVO o el SUBJUNTIVO para completar la Tabla 7. Toma como referencia la oración: "A Colón lo movió principalmente el interés en expandir la fe cristiana católica”. Fíjate en el ejemplo.

Tabla 6. Indicativo/subjuntivo

$$
\text { Afirmando y suponiendo } \rightarrow \text { INDICATIVO } \rightarrow \text { DECLARO }
$$

Fuente: elaboración propia.

Tabla 7. Indicativo/subjuntivo

\begin{tabular}{|l|l|}
\hline Es probable que & $\begin{array}{l}\text { Es probable que a Colón lo moviera el interés } \\
\text { en expandir la fe cristiana católica }\end{array}$ \\
\hline Estoy seguro de que & \\
\hline Dudo que & \\
\hline
\end{tabular}




\begin{tabular}{|l|l|}
\hline No es cierto que & \\
\hline Está claro que & \\
\hline Lo lógico es que & \\
\hline Me imagino que & \\
\hline Parece evidente que & \\
\hline No creo que/supongo que & \\
\hline Puede ser que & \\
\hline No me imagino que & \\
\hline Es difícil que & \\
\hline
\end{tabular}

Fuente: elaboración propia.

\section{Conclusiones}

Como ya se ha venido indicando, el presente trabajo se debe ubicar entre aquellos dirigidos a la creación de materiales bilingües para el aprendizaje de segundas lenguas por contenidos académicos no lingüísticos, en concreto la historia de España en español como lengua extranjera. Sobre esta premisa, lo que se ha pretendido establecer en este artículo es un posible marco - o modelo - para el desarrollo de materiales didácticos en el entorno AICLE, sin ceñirse a un grupo meta ni a un nivel de lengua concreto, sino como una visión general, pero suficientemente, creemos, detallada como para servir al propósito citado. Para tal fin, el artículo se ha centrado en tres aspectos claves, a nuestro modo de ver. En primer lugar, se han estudiado las especificidades del texto histórico. En segundo lugar, se ha hecho una aproximación a la didáctica de la historia desde planteamientos actualizados, que se fundamentan en la comprensión del pensamiento histórico. Y en tercer lugar, se ha relacionado esta didáctica de la historia con la didáctica de las lenguas, con la idea de esclarecer los puntos de convergencia entre ambas, a través del enfoque AICLE. Tras el planteamiento teórico, finalmente se ha presentado una propuesta para el desarrollo de unidades didácticas sobre la base de la teoría expuesta. 


\section{Referencias}

Achugar, M., y Schleppgrell, J. M. (2005). Beyond connectors: The construction of cause in history textbooks. Linguistics and Educational. Volumen 16, 298-318. DOI: 10.1016/j.linged.2006.02.003

Arteaga, B., y Camargo, S. (2014). Educación histórica: una propuesta para el desarrollo del pensamiento histórico en el plan de estudios de 2012 para la formación de maestros de Educación Básica. Revista Tempo e Argumento, 6(13), 110-140. Recuperado de: https://www. dgespe.sep.gob.mx/public/comunidades/historia/recursos/educacion_historica_19_de_agosto_2012.pdf

Byram, M. (2009). Perspectivas interculturales en el aprendizaje de idiomas. Madrid, España: Editorial Edinumen.

Carretero, M., y Montanero, M. (2008). Enseñanza y aprendizaje de la Historia: aspectos cognitivos y culturales. Madrid, España: Universidad Autónoma de Madrid - FLACO (Argentina) y Universidad de Extremadura.

Colón llega a América [fotografía]. (s.f.). Recuperada de https://www.elpandelospobres.com/primer-homenaje-colon

Consejo de Europa (1995). Resolución del Consejo: relativa a la mejora de la calidad y la diversificación del aprendizaje y de la enseñanza de las lenguas en los sistemas educativos de la Unión Europea. Bruselas, Bélgica: Consejo de Europa. Recuperado de https://eur-lex.europa.eu/legal-content/ ES/ALL/?uri=CELEX:31995Y0812(01)

Coyle, D., Hood, P., y Marsh, D. (2010). Content and Language Integrated Learning. Cambridge, Reino Unido: Cambridge University Press.

Dalton-Puffer, C. (2011). Content-and-Language Integrated Learning: From practice to principles? Annual Review of Applied Linguistics, 31, 182-204. DOI: 10.1017/S0267190511000092

Dalton-Puffer, C., Bauer-Marschallinger, S., Brückl-Mackey, K., Hofmann, V., Hopf, J., Kröss, L., y Lechner, L. (2017). Cognitive discourse functions in Austrian CLIL lessons: towards an empirical validation of the CDF Construct. European Journal of Applied Linguistics, 6(1), 5-29. DOI: 10.1515/eujal-2017-0028

Dallinger, S., Jonkmann, K., Hollm, J., y Fiege, C. (2015). The effect of content and language integrated learning on students. English and his- 
tory competences Killing two birds with one stone? Elsevier. Learning and Instruction, 41, 23-31. DOI: 10.1016/j.learninstruc.2015.09.003

Dodge, B. (2001). FOCUS: Five rules for writing a great WebQuest. Learning y Leading with Technology. ERIC Institute of Education Sciences, 8(28), 6-9. Recuperado de https://eric.ed.gov/?id=EJ643405

Español e india mestiza [fotografía]. (s.f.). Recuperada de https://www. 3museos.com/?pieza=de-espanol-e-india-mestiza

Estaire, S., y Zanon, J. (1994). Planning classwork: A task based approach. Oxford, Reino Unido: Heinemann.

Eurydice. (2006). Content and Language Integrated Learning (CLIL) at school in Europe. Directorate-general for education and culture. Bruselas, Bélgica: Comisión Europea. Recuperado de http://www.indire.it/lucabas/ lkmw_file/eurydice/CLIL_EN.pdf

Evangelización de América [fotografía]. (s.f.). Recuperada de http://www. celam.org/cebitepal/detalle_d.php?id=NjI

Fang, Z. (2012). Language correlates of disciplinary literacy. Top Lang Disorders, 32, 19-34. Recuperado de https://alliedhealth.ceconnection. com/files/TLD0112B-1337958964160.pdf

Ferrando, E. (2018). La historia de España en español como lengua extranjera: enseñanza por contenidos históricos en segundas lenguas (Tesis doctoral). Universidad Pablo de Olavide, Sevilla, España.

Guerrini, M. (2009). CLIL materials as scaffolds to learning. In D. Marsh, P. Mehisto, D. Wolff, R. Aliaga, T. Asikainen, M. Frigols-Martin, S. Hughes y G. Langé (eds.). CLIL practice: Perspectives from the field (Volumen 1, pp. 74-84). Finlandia: Universidad de Jyväskylä. Recuperado de_https:// englishglobalcom.files.wordpress.com/2016/10/guerrini-clil-materials-as-scaffolds-learning.pdf

Kitson, A., Steward S., y Husbands, C. (2015). Didáctica de la Historia en Secundaria Obligatoria y Bachillerato. Madrid, España: Ediciones Morata.

Lackner, M. (2012). The use of subject-related discourse functions in upper secondary CLIL history classes (Tesis doctoral). Universidad de Viena, Viena, Austria.

Llinares, A., Morton, T., y Whittaker, R. (2012).The role of Language in CLIL. Cambridge, Reino Unido: Cambridge University Press.

Lorenzo, F. (2008). Instrumental discourse in bilingual settings. An empirical study of linguistic adjustments in contents and langua- 
ge integrated learning. Language Learning Journal, 36(1), 21-33. DOI: 10.1080/09571730801988470

Martínez-Valverde, C. (1979). Consideraciones sobre la jornada de Inglaterra, 1588. Revista General de Marina, 490, 5-28. Recuperado de https:// www.todoababor.es/articulos/16-consid1588.htm

Mattozzi, I. (1999). La transposición del texto historiográfico: un problema crucial de la didáctica de la historia. Teoría y Didáctica de las Ciencias Sociales, 4, 27-56. Recuperado de https://dialnet.unirioja.es/servlet/ articulo? codigo=1313492

Mattozzi, I. (2004). Enseñar a escribir sobre la historia. Enseñanza de las Ciencias Sociales, 3, 39-48. Recuperado de https://dialnet.unirioja.es/ servlet/articulo? codigo=820726

Ministerio de Educación y Formación Profesional (2018). Estudio del programa de Historia de España de las Secciones Bilingües de la Consejería de Educación en Polonia. Recuperado de http://www.educacionyfp.gob.es/ polonia/publicaciones-materiales/publicaciones.html

Moore, P., y Lorenzo, F. (2015). Task-based learning and content language integrated learning materials design: process and product. The Language Learning Journal, 43, 334-357. DOI: 10.1080/09571736.2015.1053282

Navés, T. y Muñoz, C. (2000). Usar las lenguas extranjeras para aprender y aprender a usar las lenguas extranjeras. El futuro no nos es ajeno lo moldean nuestras acciones. Recuperado de http://www.ub.edu/filoan/ CLIL/padres.pdf

PCIC (s.f). Plan curricular del Instituto Cervantes. Recuperado de https:// cvc.cervantes.es/ensenanza/biblioteca_ele/plan_curricular/niveles/10_referentes_culturales_introduccion.htm

Prats, J., y Santacana, J. (2011). Didáctica de la Geografía y la Historia. Barcelona, España: Editorial Grao.

Pueyo, S. y Martín, I. (2014). Creación, adaptación y evaluación de materiales y recursos. Barcelona, España: Fundación Universitaria Iberoamericana.

Santisteban, A. F. (2010). La formación de competencias de pensamiento histórico. Buenos Aires, Argentina: Facultad de Humanidades y Ciencias de la Educación. Universidad Nacional de la Plata.

Seixas, P., y Norton, T. (2013). The big six Historical Thinking Concepts. Toronto, Canadá: Nelson Education.

Symcox, L., y Wischut, A. (2009). National history standards: The problem of the canon and the future of teaching history: The problem of the canon and 
the future of history teaching education". Charlotte, NC: Information Age Publishing.

Skehan, P. (1996). A framework for the implementation of task-based instruction. Applied Linguistics, 17, 38-62. DOI: 10.1093/applin/17.1.38

Stern, H. H. (1992). Issues and options in language teaching. Londres, Reino Unido: Oxford University Press.

Willis, D. y Willis, J. (2007). Doing task-based teaching. Londres, Reino Unido: Oxford Handbooks for Language Teachers. 